\title{
Effects of sildenafil citrate on pancreatic and lung complications in an experimental L-arginine-induced acute pancreatitis model
}

\author{
Baris Gulturk ${ }^{1}$, Ahmet Bozdag ${ }^{2}$, Refik Ayten², Ziya Cetinkaya², Cuneyt Kirkil², Erhan Aygen², Bilal Ustundag³ \\ Ibrahim Hanifi Ozercan ${ }^{4}$ \\ ${ }^{1}$ Department of General Surgery, Elazig Health Application and Research Centre, Health Sciences University, Elazig, Turkey \\ 2Department of General Surgery, Faculty of Medicine, Firat University, Elazig, Turkey \\ ${ }^{3}$ Department of Biochemistry, School of Medicine, Firat University, Elazig, Turkey \\ ${ }^{4}$ Department of Pathology, School of Medicine, Firat University, Elazig, Turkey
}

Gastroenterology Rev 2021; 16 (1): 29-35

DOI: https://doi.org/10.5114/pg.2021.104734

Key words: acute pancreatitis, L-arginine, pancreatitis complications, sildenafil.

Address for correspondence: Dr. Ahmet Bozdag, Department of General Surgery, Faculty of Medicine, Firat University, Elazig, Turkey, phone: +90 5336525163, e-mail: abozdag80@hotmail.com

\begin{abstract}
Aim: In this study, we aimed to investigate the effects of sildenafil citrate on acute pancreatitis and pulmonary complications of the disease.

Material and methods: In this study, we used 21 male Wistar-Albino rats weighing between 185 and $230 \mathrm{~g}$. The rats were divided into 3 groups. Group 1 rats (control group, $n=7$ ) were administered intraperitoneal $0.9 \% \mathrm{NaCl}$ injection. Group 2 (study group, $n=7$ ) and Group 3 (treatment group, $n=7$ ) rats were given $100 \mathrm{mg} / 100 \mathrm{gr}$ L-arginine twice, with an interval of $1 \mathrm{~h}$ to create acute pancreatitis. Group 3 was also administered intraperitoneal $10 \mathrm{mg} / \mathrm{kg} /$ day sildenafil citrate in 2 equal doses, $30 \mathrm{~min}$ and $12 \mathrm{~h}$ after creation of AP. The pancreas and lungs of all rats were stained with haematoxylin and eosin and examined histopathologically. Aspartate aminotransferase (AST), alanine aminotransferase (ALT), lactate dehydrogenase (LDH), interleukin (IL) $1 \alpha($ IL-1 $\alpha)$, IL-6, tumor necrosis factor $\alpha$ (TNF- $\alpha$ ), nitric oxide (NO) and ADMA levels were measured in blood samples.

Results: In the treatment group, levels of amylase, AST, ALT, LDH, IL-1, IL-6, TNF- $\alpha$, and NO were lower. In addition, pancreas and lung oedema, and perivascular inflammation were significantly less on histopathological examination when compared to the study group $(p<0.001)$. The ADMA level was significantly higher in the treatment group when compared to the control and study groups. There was no acinar cell necrosis or haemorrhage in the treatment group. However, the difference was not regarded as statistically significant because sufficient acinar cell necrosis and haemorrhage could not be created in the study group.

Conclusions: Sildenafil citrate significantly decreases various biochemical and histopathological changes in the early phase of acute pancreatitis and protects pancreatic tissue.
\end{abstract}

\section{Introduction}

Acute pancreatitis (AP) is a non-bacterial acute inflammation of the pancreas due to leakage of pancreatic enzymes into the gland's parenchyma, and their activation in that location, resulting in autodigestion of the gland [1]. To date, specific treatment methods or pharmacological agents have not been introduced that could reduce mortality and morbidity related to AP. Severe complications such as organ failure and severe metabolic disorders are seen in $20 \%$ of the patients, and the morbidity and mortality of those complications may be as high as 40\% [2]. Despite a number of experimental studies, no pharmacological agent alone has yet been proven to be sufficiently effective in treatment.

\footnotetext{
Aim

In this study, we aimed to investigate the efficiency of sildenafil citrate, an easy-to-obtain and cheap pharmacological agent with a low toxicity, in the treatment of AP and its complications, and particularly pulmonary complications.
} 


\section{Material and methods}

This study was conducted in the Experimental Animal Laboratory of Firat University Faculty of Medicine after obtaining approval from the local Ethics Committee (Date: 20.04.2008 No: 4). A total of 21 male Wistar-Albino rats weighing between 185 and $230 \mathrm{~g}$ were used in the study. The rats were housed at constant temperature and humidity in cages, with each cage housed a group consisting of 7 rats, and the animals were fed with standard pellet food and tap water. The animals were deprived of food and water starting from $12 \mathrm{~h}$ before surgery. They were divided into 3 groups, each containing 7 rats:

- Group 1 (Control group, $n=7$ ): The group in which $5 \mathrm{ml} 0.9 \% \mathrm{NaCl}$ was administered intraperitoneally;

- Group 2 (Study group, $n=7$ ): The group in which 100 mg/100 gr L-arginine (Sigma Chemical, St. Louis, MO, USA)/20\% $0.15 \mathrm{M} \mathrm{NaCl}$ was administered intraperitoneally twice to create AP, with an interval of $1 \mathrm{~h}$; - Group 3 (Treatment group, $n=7$ ): The group in which intraperitoneal sildenafil citrate (Pfizer laboratory, USA) $10 \mathrm{mg} / \mathrm{kg} /$ day was administered $30 \mathrm{~min}$ and $12 \mathrm{~h}$ after induction of AP.

After dividing into groups, the rats were followed up for $24 \mathrm{~h}$, and then surgical sampling was performed under

Table I. Histopathological scoring system

\begin{tabular}{|c|}
\hline Oedema \\
\hline $\begin{array}{l}0 \text { None } \\
1 \text { Focal widening of interlobar septa } \\
2 \text { Diffuse widening of interlobar septa } \\
3 \text { Diffuse widening of interlobar, and focal widening in } \\
\text { interacinar septa } \\
4 \text { Diffuse widening of interlobar and interacinar septa } \\
5 \text { Widening of intercellular space }\end{array}$ \\
\hline Acinar cell necrosis \\
\hline $\begin{array}{l}0 \text { None } \\
11-4 \text { necrotic cells } \\
25-10 \text { necrotic cells } \\
311-16 \text { necrotic cells } \\
4>16 \text { necrotic cells }\end{array}$ \\
\hline Haemorrhage \\
\hline $\begin{array}{l}0 \text { None } \\
1 \text { In one areas } \\
2 \text { In two areas } \\
3 \text { In three areas } \\
4 \text { In more than four areas }\end{array}$ \\
\hline Inflammation and perivascular cell infiltration \\
\hline $\begin{array}{l}\text { 0 0-1 intralobular or perivascular leucocytes } \\
12-5 \text { intralobular or perivascular leucocytes } \\
26-11 \text { intralobular or perivascular leucocytes } \\
312-20 \text { intralobular or perivascular leucocytes } \\
4>20 \text { leucocytes or diffuse microabscesses }\end{array}$ \\
\hline
\end{tabular}

general anaesthesia. In order to induce general anaesthesia, $0.25 \mathrm{ml} / 100$ gr body weight Ketamin HCL (Ketalar Flakon, Eczacıbaşı) at a concentration of $50 \mathrm{mg} / \mathrm{ml}$, and Xylazine HCL (Rhompon Flakon, Bayer) at a concentration of $20 \mathrm{mg} / \mathrm{ml}$ were administered intramuscularly to the right legs of the rats. The rats were shaved after anaesthesia, and the surgical field was cleansed with $10 \%$ povidone iodine. The rats were covered with sterile green cloths, leaving the incision areas uncovered. A midline abdominal incision was performed in all rats: skin, subcutaneous tissue, linea alba, and peritoneum were cut, and intra-abdominal structures were exposed. The pancreas was completely removed. Then the thorax was opened and the lungs were removed. Blood samples were obtained for biochemical analysis. After sampling, the rats were sacrificed by decapitation. The pancreas and lungs were kept in 6\% formaldehyde for histopathological examination. Aspartate aminotransferase (AST), alanine aminotransferase (ALT), lactate dehydrogenase (LDH), amylase, interleukin (IL) 1 (IL-1), IL-6, tumor necrosis factor $\alpha$ (TNF- $\alpha$ ), nitric oxide (NO), and ADMA levels were measured in the sera separated from the blood samples.

The samples obtained from the pancreas and the lungs were embedded in paraffin, and the sections were stained with haematoxylin and eosin. Histopathological examinations were performed under a light microscope by one pathologist blinded to the groups. Oedema, acinar cell necrosis, haemorrhage, and the degree of inflammation in the pancreas were determined according to the scoring system of Schmidt et al., and the oedema, inflammation, and haemorrhage in the lungs were scored using a 4-point (0-3) Likert scale (Table I) [3].

Serum AST, ALT, LDH, and amylase levels of the rats were measured using commercial kits and an Olympus-600 auto-analyser. Serum IL-1, IL-6, TNF- $\alpha$, NO, and ADMA levels were determined using Biosourche commercial kits and the ELISA method.

\section{Statistical analysis}

The results were presented as mean \pm standard deviation. One-way variance analysis (ANOVA) was used for statistical analysis of the data because the number of groups was more than 2. Pairwise comparisons of the groups were done with Mann-Whitney U-test. $P<0.05$ was considered as the smallest value of statistical significance.

\section{Results}

\section{Biochemical analysis findings}

Analysis of biochemical parameters revealed significantly decreased levels of amylase, AST, ALT, LDH, and NO; however, ADMA levels increased significantly. This increase was statistically significant (Table II). 
Table II. Biochemical parameters

\begin{tabular}{|c|c|c|c|c|}
\hline Parameter & $\begin{array}{c}\text { Group } 1 \\
\text { (Control) } n=7\end{array}$ & $\begin{array}{c}\text { Group } 2 \\
\text { (Study) } n=7\end{array}$ & $\begin{array}{c}\text { Group } 3 \\
\text { (Treatment) } n=7\end{array}$ & $P$-value \\
\hline AST [U/I] & $202.75 \pm 13.32^{\mathrm{a}}$ & $324.80 \pm 68.30^{b}$ & $275.40 \pm 30.96$ & $\begin{array}{l}\text { agroups } 1-2 p<0.01 \\
\text { bgroups } 2-3 p<0.01\end{array}$ \\
\hline $\mathrm{ALT}[\mathrm{U} / \mathrm{l}]$ & $64.25 \pm 13.96$ & $74.00 \pm 19.28^{a}$ & $71.00 \pm 16.56$ & a groups $1-2 p<0.01$ \\
\hline $\mathrm{LDH}[\mathrm{U} / \mathrm{l}]$ & $1988.50 \pm 142.83^{a}$ & $2469.20 \pm 301.00$ & $2134.40 \pm 175.23$ & ${ }^{a}$ groups $1-2 p<0.01$ \\
\hline Amylase [U/I] & $2220.25 \pm 161.97^{a}$ & $2706.60 \pm 279.4^{b}$ & $2451.20 \pm 261.40$ & 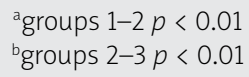 \\
\hline $\mathrm{NO}[\mathrm{mol} / \mathrm{ll}]$ & $148.25 \pm 26.64^{a}$ & $159.07 \pm 11.76^{b}$ & $135.96 \pm 11.33$ & $\begin{array}{l}\text { agroups } 1-2 p<0.01 \\
\text { bgroups } 2-3 p<0.01\end{array}$ \\
\hline ADMA [mol/l] & $1.83 \pm 1.05^{\mathrm{a}}$ & $6.25 \pm 2.17$ & $6.41 \pm 3.11$ & agroups $1-2 p<0.01$ \\
\hline
\end{tabular}

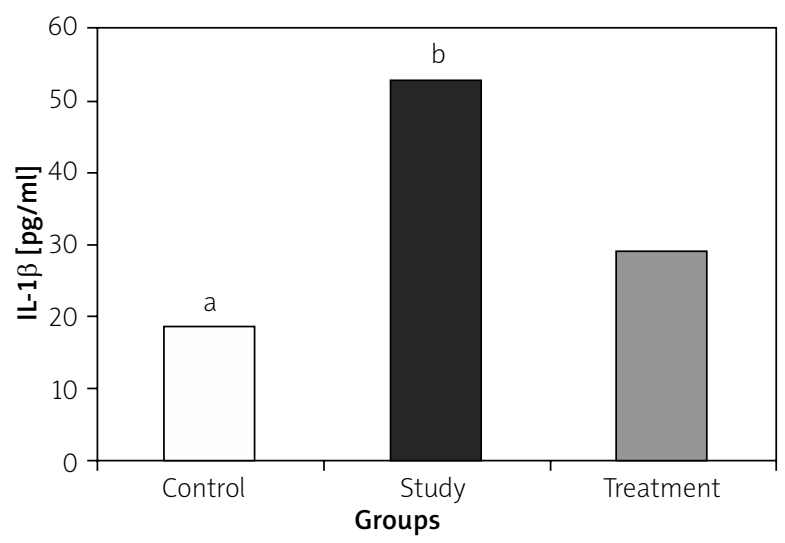

Figure 1. IL-1 $\beta$ level

\section{Immunological findings}

IL-1, IL-6, and TNF- $\alpha$ levels were significantly lower in the treatment group when compared to the study group (Figures 1-3).

\section{Histopathological findings}

Histopathological examination showed significantly less pancreatic oedema and infiltration in the treatment

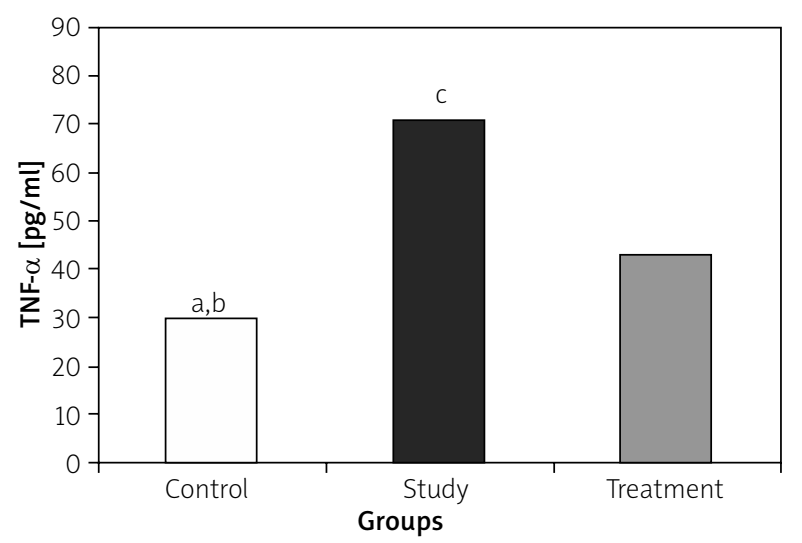

Figure 3. TNF- $\alpha$ level

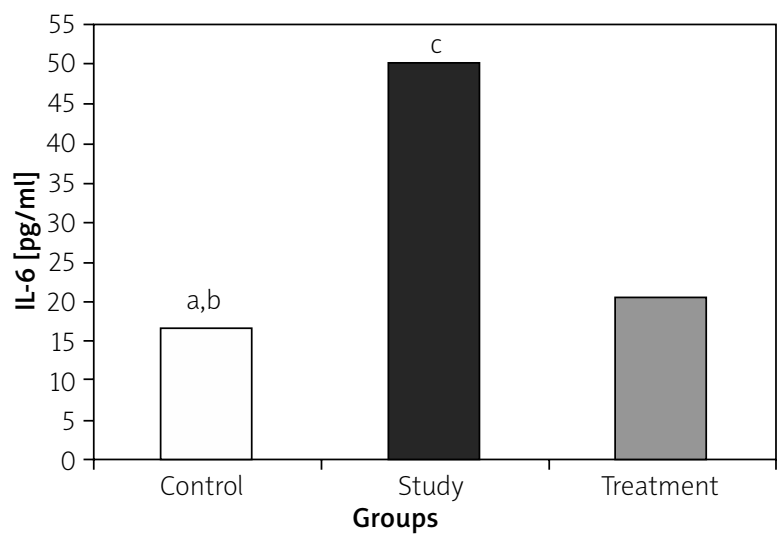

Figure 2. IL-6 level

group when compared to the group with pancreatitis. There was no sufficient amount of acinar cell necrosis and haemorrhage in the pancreatitis group, and acinar cell necrosis or haemorrhage were not seen in the control and treatment groups. The differences between treatment and pancreatitis groups were found not to be statistically significant because sufficient acinar cell necrosis and haemorrhage did not develop in the pancreatitis group (Figures 4-6).

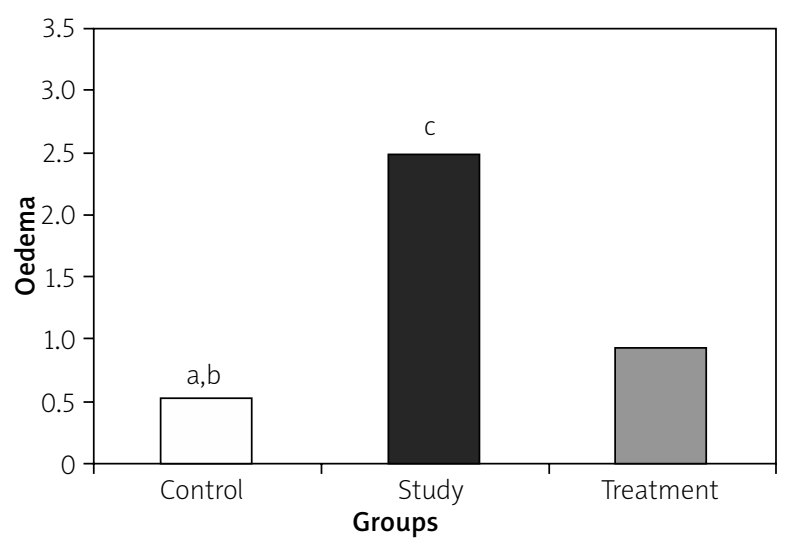

Figure 4. The level of oedema in pancreatic tissue 


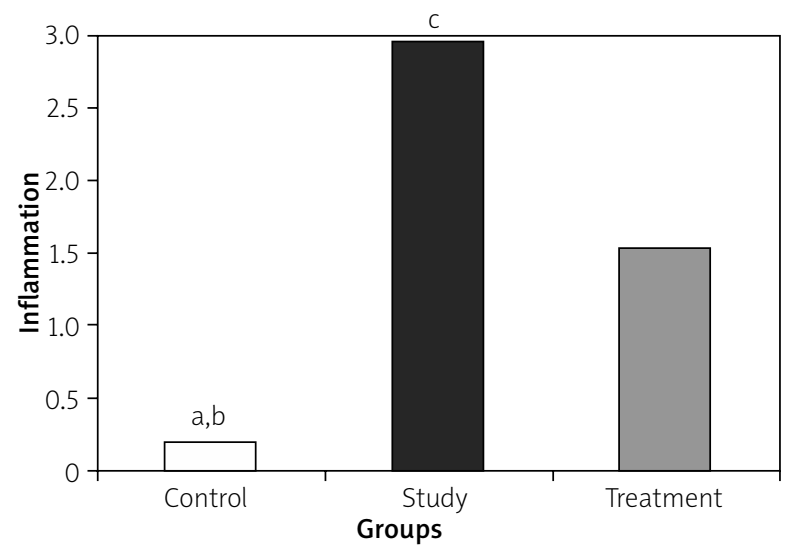

Figure 5. The inflammation level in pancreas

Histopathological examination of lungs showed significantly less oedema and infiltration in the treatment group when compared to the pancreatitis group. There was no haemorrhage in the control group, and the degree of haemorrhage was the same in the pancreatitis and the control groups (Figures 7-10).

\section{Discussion}

AP is an inflammatory disease that typically presents with abdominal pain and high pancreatic enzyme levels in the blood and urine. The clinical presentation of AP may vary and involves a wide clinical picture ranging from mild abdominal pain to multi-organ failure and death. The most frequent symptoms are abdominal pain, nausea, and vomiting. During the course of the disease, various complications may develop, which may increase mortality and morbidity, such as sepsis, shock, and pulmonary and renal failure. Although a number of studies have been performed investigating the aetiology of AP, its pathophysiology has not been clearly put forward. Therefore, there are no efficient methods for its treatment.

AP is still an important cause of morbidity and mortality. Its basic treatment includes close monitoring of vital signs, maintaining fluid and electrolyte balance, and planning treatment for possible complications. To date, none of the pharmacological agents have been proven to be beneficial alone in the treatment of AP. Several agents including aprotinin, gabexate mesilate, glucagon, calcitonin, methylprednisolone, and $\mathrm{N}$-acetylcysteine have been used in studies; however, none of them was demonstrated to be beneficial when used alone [4-6]. Free oxygen radicals were shown to play role in the pathogenesis of AP. Hence, a number of experimental studies showed that use of antioxidants decreased the severity of AP as well as the prevalence of complications. In these studies,
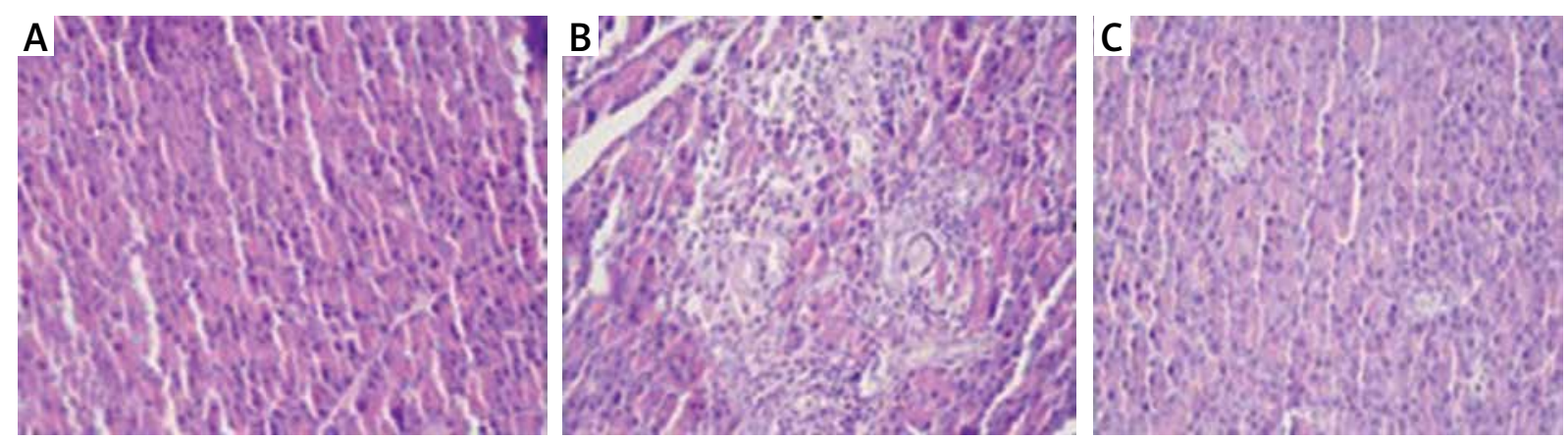

Figure 6. A - Normal pancreas tissue (Control group), B - Pancreatitis group (Study group), C - The group treated (Treatment group) (HE 200x)

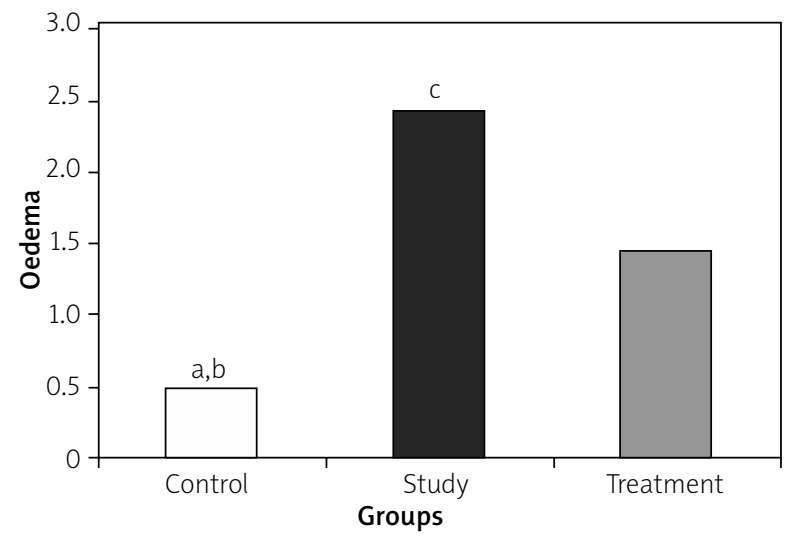

Figure 7. The degree of oedema in the lungs

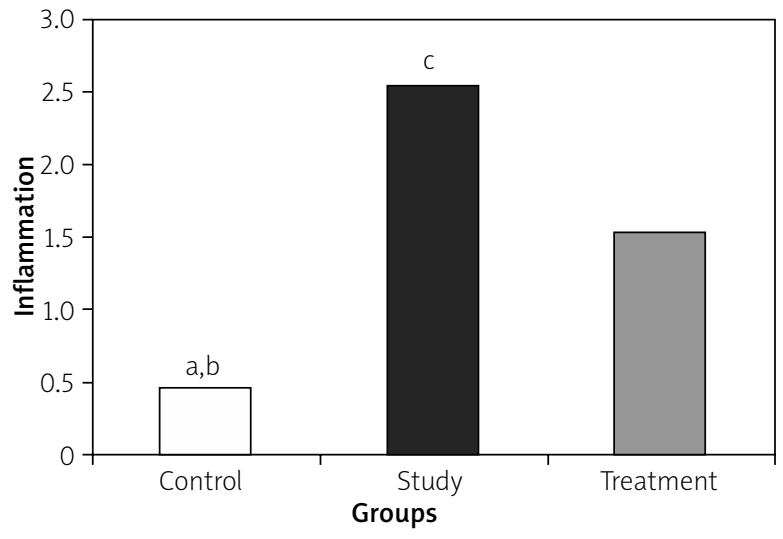

Figure 8. The degree of inflammation in the lungs 
biochemical parameters and histopathological examination both showed that antioxidants decreased the severity of AP [7, 8].

Although the activating factor is not known in the pathogenesis of AP, it has been known enzymes synthesized in the pancreas leak into the interstitial space, and activation of proteolytic enzymes and particularly trypsinogen starts the pancreatic autodigestion process [8]. Proteolytic enzymes cause liberation of free oxygen radicals, which play an important role in the pathogenesis of AP. Free oxygen radicals result in peroxidation of cell membrane lipids, resulting in destruction of cell membrane and death of cell. This process causes an increase in free oxygen radicals and other inflammatory mediators (IL-1, IL-6, IL-8, IL-10, TNF- $\alpha$ ). The effects of those mediators activate leucocytes. Activated leucocytes release more inflammatory mediators. In addition, the adhesion molecules on the surface of the neutrophils interact with vascular endothelium, causing increased permeability of the endothelial layer of the arterioles and venules. Increased permeability facilitates extravasation of plasma and erythrocytes causing tissue oedema and microhaemorrhages [9-14].

The chemotactic factors released from injured tissues cause leucocyte accumulation. Accumulated leucocytes occlude the capillary lumen and impair microcirculation. Impaired microcirculation causes ischaemia. More free oxygen radicals are generated due to ischaemia- reperfusion. These chain reactions create a vicious cycle [9-14]. The systemic effects of released inflammatory mediators cause a systemic injury, although the injury is first limited to pancreas. The clinical reflections of this mechanism may be shock, acute respiratory distress syndrome, and multisystem organ failure. Mortality is approximately $50-90 \%$ in this picture, with a grave clinical course. Sixty percent of the patients usually die due to pulmonary complications, in the first week. Later, sepsis is the cause of mortality [14, 15]. In this study, we used sildenafil citrate and aimed to investigate its protective effect in the pancreas as

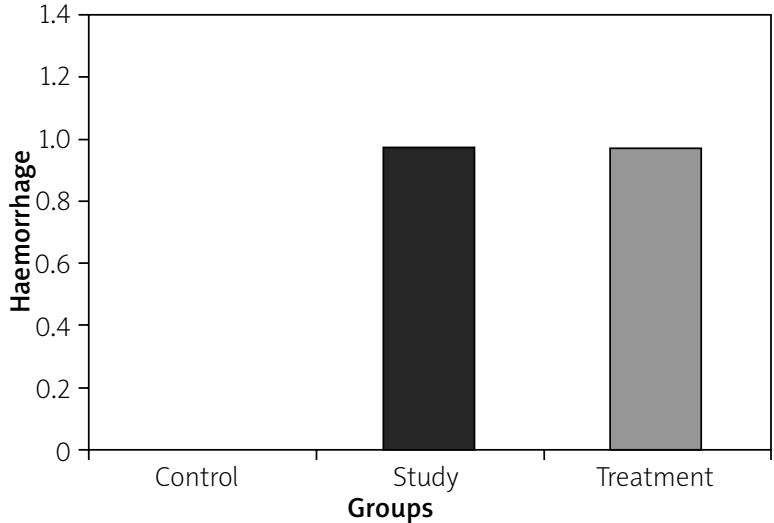

Figure 9. Degree of haemorrhage in the lungs

well as lungs, where complications related to pancreatitis are common.

There are a number of experimental pancreatitis models. We used L-arginine to create pancreatitis. Previous experimental studies showed that basic amino acids such as L-arginine caused injury and AP in the rat pancreas when used in high doses. In an experimental study, Czako et al. showed that intraperitoneal injection of L-arginine caused reversible AP [16]. However, they could not clearly explain the mechanism of the pathological changes in the pancreas. An experimental study performed in our clinic by Bülbüller et al. demonstrated that intraperitoneal injection of L-arginine resulted in a reversible AP picture $[17,18]$. In that study, L-arginine solution at a dose of $250 \mathrm{mg} / 100 \mathrm{~g} / \mathrm{kg}$, prepared with $20 \% 0.15 \mathrm{M} \mathrm{NaCl}$ was administered intraperitoneally twice, with a 1-hour interval. In our study, we aimed to use the lowest amount of L-arginine that caused AP. Therefore, we determined the L-arginine dose as $100 \mathrm{mg} / 100 \mathrm{~g} / \mathrm{kg}$, and administered this dose twice with a 1-hour interval. At the end, we showed development of reversible AP both with biochemical parameters and histopathological examination.

Sildenafil citrate has been used in the treatment of erectile dysfunction throughout the world, and it has
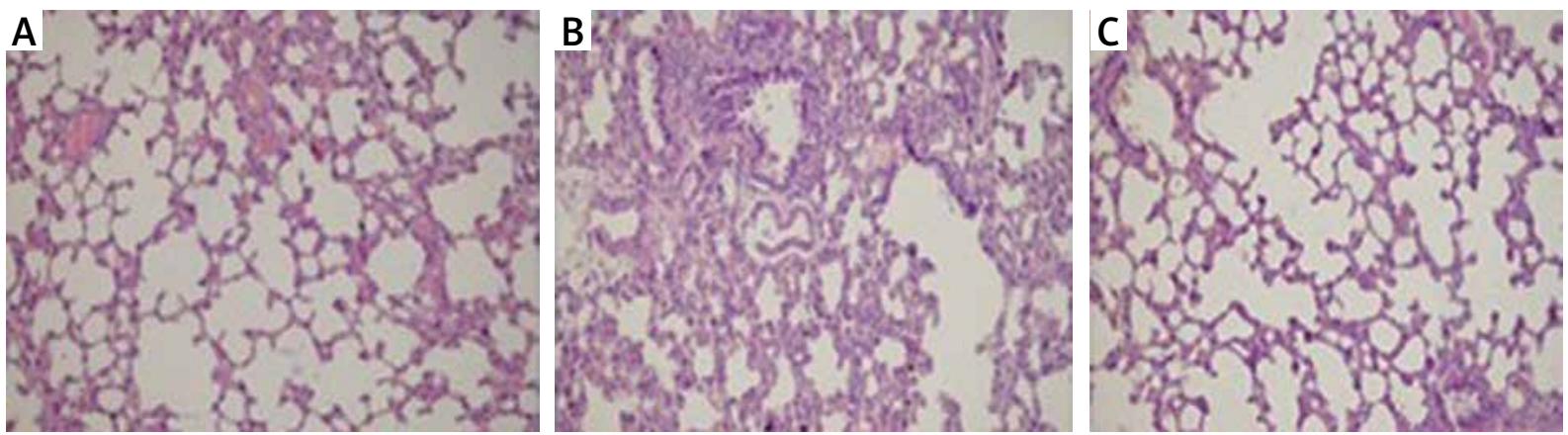

Figure 10. A - Normal lung tissue (Control group), B - Lung tissue in the pancreatitis group (Study group), C - Lung tissue in the treatment group (HE 200x) 
recently been used in the treatment of other diseases, primarily pulmonary hypertension [19]. Sildenafil citrate is a phosphodiesterase type 5 (PDE 5) enzyme inhibitor, and it causes relaxation in the smooth muscles by increasing cGMP. In an experimental study, Sarıfakıoglu et al. reported that sildenafil citrate increased flap survival. The authors stated that this was due to two basic effects of sildenafil citrate: first, inhibition of platelet aggregation, decreased vascular thrombosis, and hence inhibition of impaired microcirculation; and second, vasodilation and increased blood flow in the smooth muscles [19]. As a result, sildenafil citrate maintains circulation, and protects tissues against hypoxia and ischaemia. As is known, hypoxia and ischaemia increase the severity of inflammation in tissues. In addition, sildenafil citrate protects tissues against ischaemia reperfusion. Studies showed that sildenafil citrate has an anti-inflammatory effect by inhibiting production of free oxygen radicals [20-22].

In our study, intraperitoneal administration of L-arginine solution was shown to result in reversible AP in rats, as demonstrated by increased biochemical parameters in blood and histopathological examination of pancreas. AST, ALT, amylase, LDH, an ADMA levels were higher in the study group than in the control group. There was significant oedema and perivascular infiltration in the pancreas. After creation of pancreatitis, sildenafil citrate was administered intraperitoneally, and both biochemical parameters and histopathological findings showed significant improvements in the treatment group. Levels of AST, ALT, amylase, LDH, and NO were statistically significantly lower in the treatment group when compared to the study group; however, ADMA levels were higher in the treatment group. However, the difference in ADMA levels was not statistically significant. These results indicated that pancreatitis-related increase in ADMA decreased NO synthesis, and this caused decreased NO levels in both the study and treatment groups. A decrease in NO level impairs circulation by decreasing pancreatic vasodilation. Although more injury was expected due to those biochemical parameters, the use of sildenafil citrate in the treatment group increased intracellular cGMP levels with a mechanism independent of NO, caused vasodilation, and protected the pancreas from injury. On histopathological examination, the study group had significantly more oedema and perivascular inflammation in the pancreas and lungs when compared to the control group; however, there was significantly less oedema, and particularly less perivascular inflammation, in the treatment group. Little acinar cell necrosis and haemorrhage was seen in the study group, while those findings were not seen in the treatment group. The difference between the groups was not regarded as significant because an insufficient amount of acinar cell necrosis and haemorrhage developed in the study group; we suppose that this was related to the low dose of L-arginine used for the creation of pancreatitis.

\section{Conclusions}

Sildenafil citrate prevents impairment of microcirculation in the early phase of pancreatitis by causing vasodilation and inhibiting platelet aggregation, and this way it protects the pancreas from hypoxia and ischaemia, and ischaemia reperfusion. It shows anti-inflammatory and antioxidant effects by inhibiting synthesis of free oxygen radicals and other inflammatory cytokines. Therefore, when used in the early phase of AP, sildenafil citrate significantly downgrades biochemical and histopathological changes in the pancreas and lungs, and it protects those organs. These results indicate that sildenafil citrate may be used in clinics because it does not have any reported toxicity in cases with AP. However, further studies are needed on this subject.

\section{Conflict of interest}

The authors declare no conflict of interest.

\section{References}

1. Yamanel L, Mas MR, Comert B, et al. The effect of activated protein $\mathrm{C}$ on experimental acute necrotizing pancreatitis. Crit Care 2005; 9: 184-90.

2. Bülbüller N, Dogru O, Umac H, et al. The effects of melatonin and pentoxiphylline on Larginine induced acute pancreatitis. Ulus Travma Acil Cerrahi Derg 2005; 11: 108-14.

3. Schmidt J, Rattner DW, Lewandrowski K. A beter model of acute pancreatitis for evaluating therapy. Ann Surg 1992; 215: 44-56.

4. Zou WG, Wang DS, Lang MF, et al. Human interleukin 10 gene therapy decreases the severity and mortality of lethal pancreatitis in rats. J Surg Res 2002; 103: 121-6.

5. Rongione AJ, Kusske AM, Reber HA, et al. Interleukin-10 reduce circulating levels of serum cytokines in experimental pancreatitis. J Gastrointest Surg 1997; 1: 159-65.

6. Szaboles A, Reiter RJ, Letoha T, et al. Effect of melatonin on the severity of L-arginine induced experimental acute pancreatitis in rats. World J Gastroenterol 2006; 12: 251-8.

7. Oruc O, Inci K, Aki FT, et al. Sildenafil attenuates renal ischemia reperfusion injury by decreasing leukocyte infiltration. Acta Histochem 2010; 112: 337-44.

8. Kukreja RC, Salloum F, Das A, et al. Pharmacological preconditioning with sildenafil: basic mechanisms and clinical implications. Vascul Pharmacol 2005; 42: 219-32.

9. Ranson JHC. Acute pancreatitis: pathogenesis, outcome and treatment. Clin Gastroenterol 1984; 13: 843-63.

10. Kaska M, Pospisilova B, Slizova D. Pathomorphological changes in microcirculation of pancreas during experimental acute pancreatitis. Hepatogastroenterology 2000; 47: 1570-4. 
11. Eubanks JW, Sabek O, Kotb M, et al. Acute pancreatitis. Induced cytokine production in endotoxin-resistant mice. Ann Surg 1998; 227: 904-11.

12. Norman J. The role of cytokines in the pathogenesis of acute pancreatitis. Am J Surg 1998; 175: 76-83.

13. Rau B, Poch B, Gansauge F, et al. Pathophysiologic role of oxygen free radicals in acute pancreatitis. Ann Surg 2000; 231: 352-60.

14. Dobosz M, Hać S, Wajda Z. Does nitric oxide protect from microcirculatory disturbances in experimental acute pancreatitis in rats? Int J Microcirc Clin Exp 1996; 16: 221-6.

15. De Beaux AC, Ross JA, Maingay JP, et al. Proinlammatory cytokine release by peripheral blood mononuclear cells from patients with acute pancreatitis. Br J Surg 1996; 83: 1071-5.

16. Czakó L, Takacs T, Varga IS, et al. Involvement of oxygen-derived free radicals in Larginine-induced acute pancreatitis. Dig Dis Sci 1998; 43: 1770-7.

17. Czakó L, Takacs T, Varga IS, et al. The pathogenesis of L-arginine induced acute necrotizing pancreatitis: inlammatory mediators and endogenous cholecytokinin. J Physiol 2000; 94: 43-50.

18. Tani S, Itoh H, Okabayashi Y, et al. New model of acute necrotizing pancreatitis induced by excessive doses of arginine in rats. Dig Dis Sci 1990; 35: 367-74.

19. Lledo-Garcia E, Subira-Rios D, Rodriguez-Martinez D, et al. Sildenafil as a protecting drug for warm ischemic kidney transplants: experimental results. J Urol 2009; 182: 1222-5.

20. Zusman RM, Morales A, Glasser DB, et al. Overall cardiovascular proile of sildenail citrate. Am J Cardiol 1999; 83: 35C-44C.

21. Sarifakioglu N, Gokrem S, Ateş L, et al. The influence of sildenafil on random skin flap survival in rats: an experimental study. Br J Plastic Surgeons 2004; 57: 769-72.

22. Armstrong DM, Armstrong Ada C, Figueiredo RC, et al. Sildenail citrate protects skeletal muscle of ischemia-reperfusion injury. Immunohistochemical study in rat model. Acta Cirúrgica Brasileira 2013; 28: 282-7.

Received: 23.10 .2019

Accepted: 16.04 .2020 